\title{
ROLE OF SUBSTANCE P IN PANCREATITIS AND ASSOCIATED DISEASES
}

\author{
Vaishnavi Sundar ${ }^{1}$, Shalini Ramasamy ${ }^{2}$, Sanjana Vimal ${ }^{1}$, Anupam Dutta ${ }^{1}$, Kshitija Joshi $^{1}$, \\ Venkatraman Manickam ${ }^{2}$, Ramasamy Tamizhselvi ${ }^{1}$ *
}

${ }^{1}$ Department of Biotechnology, School of Biosciences and Technology, Vellore Institute of Technology, Vellore 632014, Tamil Nadu, India.

${ }^{2}$ Department of Biomedical Sciences, School of Biosciences and Technology, Vellore Institute of Technology, Vellore 632014, Tamil Nadu, India.

Received - July 25, 2021; Revision - October 01, 2021; Accepted - October 11, 2021

Available Online - October 30, 2021

DOI: http://dx.doi.org/10.18006/2021.9(5).580.590

\section{KEYWORDS \\ Substance P \\ Inflammation \\ NK1R}

Pancreatic cancer

Pancreatitis

\begin{abstract}
Substance P (SP) is a neuropeptide that has its place in the tachykinin family and helps in the transmission of neurogenic signals. SP is also a neuromodulator that plays a crucial part in pain during inflammatory processes. It is produced by the capsaicin-sensitive unmyelinated $\mathrm{C}$ fibers sensory neurons by the central and peripheral nervous systems. Substance $\mathrm{P}$ is known as a critical primary responder to most of the extreme stimuli, i.e., specifically those with the ability to destabilize the biological integrity. Hence, SP can be considered as an instantaneous system for defense, stress, healing, etc. SP is known to perform a vital role in neurogenic inflammation and the pathophysiology of acute pancreatitis. Out of these, neurogenic inflammation is responsible for acute interstitial pancreatitis as a result of oedema. SP binds itself to the G-protein coupled neurokinin-1 receptor and causes plasma leakage, cell proliferation, and invasion resulting in pancreatic cancer. SP along with comparable neuropeptides seems to be crucial targets with the capability of satisfying several unfulfilled medical requisites. This review article mainly focuses on compiling the available evidence to show that SP could be a novel therapeutic target for pancreatic diseases, and more exploration into the SP signaling pathways is the call of the hour.
\end{abstract}

* Corresponding author

E-mail: tamizhselvi.r@vit.ac.in (Ramasamy Tamizhselvi)

Peer review under responsibility of Journal of Experimental Biology and Agricultural Sciences.

Production and Hosting by Horizon Publisher India [HPI] (http://www.horizonpublisherindia.in/).

All rights reserved.
All the articles published by Journal of Experimental Biology and Agricultural Sciences are licensed under a Creative Commons Attribution-NonCommercial 4.0 International License Based on a work at www.jebas.org.

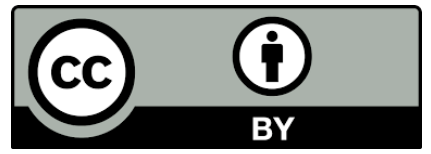




\section{Introduction}

Peptides are an essential category of molecules that play vital roles as transmitters as well as modulators in our nervous system. Out of these peptides, Substance $\mathrm{P}$ (SP) is considered to be highly characterized in terms of its distribution and function. SP is a wellknown 11 amino acid (Arg-Pro-Lys-Pro-Gln-Gln-Phe-Phe-GlyLeu-Met-NH2) containing neuropeptide with a total positive charge in physiological pH (Qureshi, 2007). SP is synthesized by neuronal and non-neuronal cells along with immune cells. SP is proven to exert its biological activities via $G$ protein-coupled neurokinin or tachykinin receptors (NKRs or TACRs), namely NK1R, NK2R, and NK3R. It is also known to engage in an essential role in asthma, arthritis in addition to several other inflammatory processes (Keeble \& Brain, 2004).

SP is released from primary sensory nerve filaments which are a part of the tachykinin family and have been associated with a multitude of physiologic activities (di Mola \& di Sebastiano, 2008; Hökfelt et al., 2001). SP is extensively expressed in both central as well as peripheral nervous systems along with peripheral tissues like $\mathrm{B}$ and $\mathrm{T}$ cells in an autocrine or paracrine manner (Esteban et al., 2006). NK1R, a vital receptor of SP, is also expressed excessively in several standards and neoplastic cell types (Guha et al., 2005; Muñoz et al., 2010; Muñoz \& Rosso, 2010). SP regulates loads of biological functions and has also been concerned with neurogenic inflammatory reactions, pain, and depression. Nerves, enclosing SP, are known to innervate primary lymphoid organs, the thymus, and the bone marrow, as well as secondary lymphoid organs including the lymph nodes, spleen, tonsils, etc. (Marriott \& Bost, 2002). This advocates the fact that SP may perhaps act as a facilitator between nervous and immune systems. Besides their synthesis from neurons, SP coupled with its receptor NK1R is well known to be expressed in several other immune cell types.

The release of SP primarily influences the triggering of the inflammatory reaction cascade in the marked tissue. SP is capable of enhancing the release of the pro-inflammatory facilitators towards the peripheral tissue. For instance, SP can intensify the synthesis and secretion of prostaglandin E2 (Lotz et al., 1987), the secretary process of lysosomal enzymes (Johnson \& Erdös, 1973), along with the secretion of interleukin 1 coupled with the neutrophil chemoattractant interleukin 6 (Lotz et al., 1988). In the course of inflammation, entering macrophages express NK-1 receptors (Marriott \& Bost, 2002) proposing that SP inside the peripheral tissues can prolong the inflammatory cascade.

It is well established that SP is also present in the pancreas and it may act identical to a neurotransmitter for the sensory afferent nerves in the pancreas. Receptors dedicated to SP have also been discovered on acinar cells present in the pancreas of guinea pigs. Furthermore, the neuropeptide exhibits as a secretagogue, accelerating the process of secretion of amylase from acinar cells through a mechanism involving the $G$ protein, the phospholipase along with inositol phosphate and calcium-mediated reactions in the species (Song et al., 1988; Sjödin et al., 1991; Sjödin et al., 1994). Pancreatic acinar cells of the rat do not exhibit receptors for SP and the concerned neuropeptide does not promote the release of enzymes from the rat's acinar cells (Song et al., 1988).

The expressions of both NK-1 receptors besides substance $\mathrm{P}$ levels present in acinar cells are amplified during the development of pancreatitis induced by the cerulean (Bhatia et al., 1998). Cerulein stimulated pancreatitis depicted by pancreatic plasma leakage, raised myeloperoxidase (MPO) levels in both pancreas and lungs was also considerably diminished in NK1 knockout mice, showing that SP significantly plays a part in acute pancreatitis $\mathrm{s}(\mathrm{AP})$ and AP allied lung injury (Bhatia et al., 1998; Grady et al., 2000). Additionally, an NK1 receptor inhibitor (CP-96345) has been demonstrated to defend against AP and accompanying lung injury stimulated by injecting cerulein in rats and mice (Grady et al., 2000; Lau et al., 2005). The employment of both NK1 in cooperation with neural endopeptidase knockout mice established that SP plays a crucial role in regulating the toxicity in the case of the necrotizing classical pancreatitis model (Maa et al., 2000).

\section{Substance $\mathbf{P}$ Mediated Physiological Mechanisms in the Pancreas}

As mentioned above, SP is known to interact with three specific $\mathrm{G}$ protein-coupled neurokinin or tachykinin receptors, namely the NK1-R plus NK2-R, as well as NK3-R, with varying affinities (Helke et al., 1990). In the case of the mouse pancreas, the presence of the NK1 receptor is already identified with the help of immunohistochemistry in acinar cells. However, it is undetermined whether the other cells localized in the pancreas, like neurons or endothelial cells, are capable of expressing neurokinin receptors or not.

The functional aspect of SP in the case of the pancreas is not entirely understood to date. This is primarily entitled to the complications involved in the neurohormonal communications that are known to affect the secretory process of the exocrine pancreatic region. Secretin stimulated secretion concerned with the exocrine pancreas is constrained using SP in rats (Zhou et al., 2018). Likewise, SP obstructs; equally, the basal and secretin promoted fluid release in isolated pancreatic duct cells of rats (Ashton et al., 1990). It is also well known that intravenous SP increases the amylase secretion induced by venous infusion of cerulein in the sedated intact rat (Katoh et al., 1984) but then 
prevents the secretion of pancreatic protein triggered by cerulean (Konturek et al., 1981). Venous administration of SP induces countless systemic consequences that may modify the pancreatic secretion containing hypotension, variations in case of visceral blood flow (v Euler \& Gaddum, 1931; Konturek et al., 1981), hyperglucagonemia, as well as hyperglycemia (Horiuchi et al., 1993; Edwards \& Bloom, 1994; Schönfeld \& Müller, 1994). Therefore, SP intravenous administration perhaps does not imitate the biological effect of this locally operating neuropeptide in numerous ways.

Research has reported that SP antagonizes cholecystokinin (CCK) analogcerule in stimulated amylase secretion and pancreatic discharge of juice caused by the administration of secretin in the case of rat pancreas. However, the above effects can be partly reversed by blocking either the NK1-R or the NK2-R. SP stimulated blockage of exocrine secretion contains a specific neural mechanism. The stimulus concerned with sensory nerves caused by capsaicin additionally results in a dose-related constraint of the exocrine secretory cascade, which is somewhat blocked by antagonists of the concerned NK1 receptor. These results further suggest that the peptidergic sensory nerves are essential in the secretory regulation of the exocrine pancreatic region (Figure 1) as suggested by Kirkwood et al. (1999).

\section{Neurogenic Mechanism of Inflammation}

Several tissues such as the skin, eye, joints along with systems such as the digestive, respiratory, etc. have shown the presence of neurogenic inflammation. The activity of SP is primarily vasoconstrictive. Contrariwise, there are descriptions that SP can perform vasodilation in part by triggering the secretion of histamine from the mast cells (Owman, 2019) via straight action, which is not reliant on the secretion of histamine. Inhibitors concerned with the NK1 receptor might also eradicate the vasodilation caused by SP (Couture \& Cuello, 1984; Xu et al., 1991). Calcitonin gene correlated peptide is an effective vasodilator that, in low concentrations, can perform vasodilation through direct action (Yan et al., 2019). In the case of visceral tissues, neurogenic inflammation cannot be considered merely as a pathophysiological mechanism resulting in various diseases because it also takes part in the tissue response mechanism to injury. Neurogenic inflammation appears as an adaptive reaction, advocating rapid escalations in tissue substances by priming cells for neighboring defense and increasing fluid transportation to separate the bacteria and toxins. Still, this course of action may turn maladaptive, as noticed in the case of asthma, migraine as well as arthritis (Holzer \& Barthó, 1996).

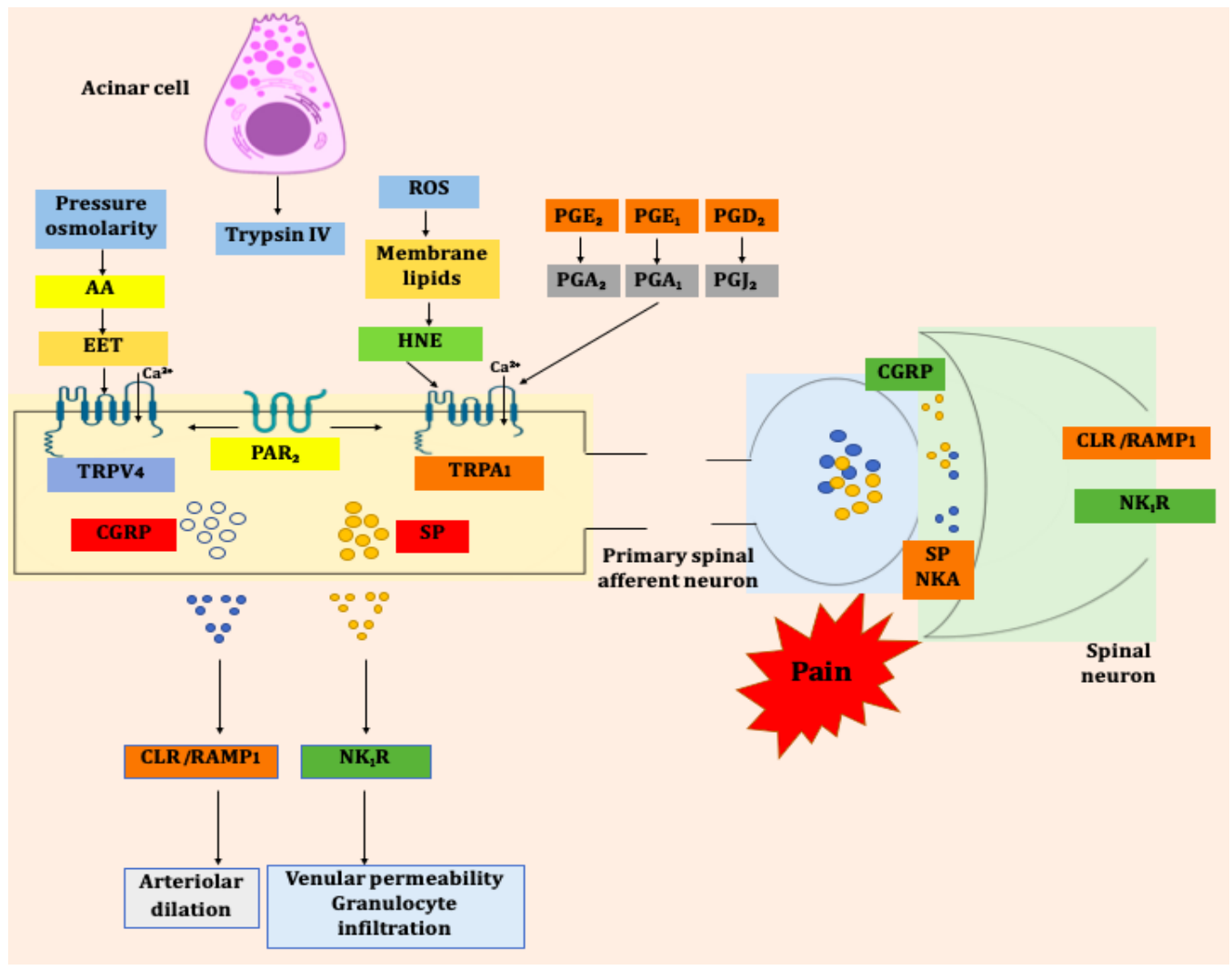

Figure 1 Illustration of SP molecular mechanism in pancreas 
Table 1 Available Clinical Trials of SP against Pancreatic Diseases

\begin{tabular}{|c|c|c|c|c|c|}
\hline Drug Name & Condition/Disease & Therapeutic Mechanism & $\begin{array}{c}\text { Clinical Trial } \\
\text { Phases }\end{array}$ & $\begin{array}{l}\text { Time } \\
\text { period }\end{array}$ & Status \\
\hline Rolapitant & $\begin{array}{l}\text { Prevention of } \\
\text { chemotherapy-induced } \\
\text { nausea and vomiting } \\
\text { (CINV). }\end{array}$ & $\begin{array}{l}\text { Rolapitantorvarubibelongs to a class } \\
\text { of anti-cancer agents that is aselective } \\
\text { NK1 receptor antagonist. Given in } \\
\text { combination with other anti-vomiting } \\
\text { drugs in emetogenic cancer } \\
\text { chemotherapy. }\end{array}$ & Phase 3 & 2011-2016 & completed \\
\hline $\begin{array}{c}18 \mathrm{~F}]- \\
\text { Labeled Substance } \\
\text { P Antagonist } \\
\text { Receptor } \\
\text { Quantifier }\end{array}$ & Pancreatic Cancer & $\begin{array}{c}\text { Non-randomized interventional trial to } \\
\text { study proportion of pancreatic tumors } \\
\text { detected by [18F]-labeled substance P } \\
\text { antagonist receptor quantifier positron } \\
\text { emission tomography. }\end{array}$ & Phase 1 & 2007-2012 & completed \\
\hline $\begin{array}{l}\text { Palonosetron and } \\
\text { Fosaprepitant }\end{array}$ & $\begin{array}{l}\text { Cholelithiasis- } \\
\text { Postoperative nausea } \\
\text { and vomiting }\end{array}$ & $\begin{array}{l}\text { Cholelithiasis-PONV resultant } \\
\text { pancreatitis. ComparisonbetweenSP } \\
\text { antagonists Palonosetron and } \\
\text { FosaprepitantintheProfilaxis of } \\
\text { PONVin women. }\end{array}$ & Phase 4 & 2018-2019 & Recruiting \\
\hline Aprepitant & Pancreatitis & $\begin{array}{l}\text { Reduce the risk of pancreatitis by } \\
\text { blocking SP/NK1R mechanism in } \\
\text { patients undergoing Post-Endoscopic } \\
\text { Retrograde Cholangiopancreatography } \\
\text { (ERCP). }\end{array}$ & N.A & $2008-2015$ & Completed \\
\hline $\begin{array}{c}\text { Substance P } \\
\text { biomarker }\end{array}$ & Acute pancreatitis & $\begin{array}{l}\text { Clinical Evaluation of Novel } \\
\text { Biological Markers for the Prediction } \\
\text { of Severe Acute Pancreatitis. }\end{array}$ & N.A & 2008-2012 & Completed \\
\hline Paricalcitol & Pancreatic Cancer & $\begin{array}{l}\text { Man-made Vitamin D that blocks the } \\
\text { signal in cancer tumour cells that leads } \\
\text { to growth and spreading of tumour }\end{array}$ & Phase 2 & 2020 & Recruiting \\
\hline
\end{tabular}

The process of injecting SP to mice triggers leakage of plasma from the postcapillary venules located in the pancreas and this consequence can be hindered by inhibitors of the NK1 receptor (Figini et al., 1997). Additionally, it has been established that the genetic elimination of the NK1 receptor from mice decreases the seriousness of the experimental mice model of pancreatitis (Bhatia et al., 1998). These outcomes show that SP is one of the essential facilitators of pancreatic inflammatory reactions.

The aforementioned support indicates a vital role of SP as one of the pro-inflammatory mediators throughout pancreatitis; however, its function as a mediator concerned with pain besides neurogenic inflammation is quite unspecified. As discussed above, SP is capable of stimulating the activation of several proinflammatory cytokines due to its function as a pro-inflammatory factor. These released cytokines are capable of producing hyperalgesia (Watkins \& Maier, 2000). Hence, this might be one of the several mechanisms causing pancreatic pain. The manifestation of SP, as well as IL-8 in the case of pancreatitis, are interconnected (Di Sebastiano et al., 2000). In addition, the upregulation of receptor NK1 located in the pancreatic region is associated with aspects of pain in pancreatitis (Shrikhande et al., 2001).

\section{Role of SP in Pancreatitis}

Pancreatitis is a state of disorder in which the primary pathology is related to the inflammatory condition of the pancreatic tissue. The classification of the condition generally depends on the duration or course of progression of the disease. Acute pancreatitis (AP) can be described as a self-limited, mild state, usually associated with higher serum levels of the pancreatic digestive enzymes (Singer et al., 1985). Chronic pancreatitis (CP) frequently represents the gradual damage to the pancreatic tissue by a recurrent outburst of silent or symptomatic AP (Vera-Portocarrero \& Westlund, 2005).

The mechanisms followed by SP to intensify the rigorousness associated with pancreatitis are not evident. Studies conducted denote the probable role of SP in inflammatory reactions and the fact that the neuropeptide primarily acts on the endothelial cells to escalate vascular penetrability and stimulates the formation of edema (Bhatia et al., 1998).

\subsection{Acute Pancreatitis}

The CCK analog, cerulein stimulated, NK1 receptor facilitated, plasma leakage in AP is probably associated with the intrapancreatic secretion of SP. Pancreatic levels of SP escalate 
after cerulein administration (Bhatia et al., 1998). As already mentioned, the pathway involved in the cerulein stimulatory secretion of SP in the pancreatic tissue is not well understood. In several other tissues, several toxic chemicals along with mechanical or thermal stimuli trigger the subgroups of afferent neurons that include SP, which is subsequently released either centrally or peripherally, leading to stimulation and internalization of the NK1 receptor (Bowden et al., 1994; Mantyh et al., 1995). It appears that the sensory nerves are stimulated during AP progression resulting in the secretion of intrapancreatic SP and activation of the above-mentioned NK1 receptor (Grady et al., 2000). Transient receptor potential vanilloid type 1 (TRPV1) conduits are situated on the primary sensory neurons, which, when activated, instigate the neuronal secretion of accumulated SP. It was confirmed in vivo that the capsazepine, a TRPV1 inhibitor, considerably diminished inflammatory reactions and pancreatic tissue injury in caerulein-induced AP (Nathan et al., 2001). Contrary-wise, the activation of TRPV1 via capsaicin initiated the release of SP and amplified caerulein stimulated AP (Hutter et al., 2005). The consequences caused by SP can be stopped by employing enzymatic degradation with the help of neutral endopeptidase (NEP). Genetic deletion of these NEP intensifies pancreatic tissue damage and accompanying lung injury and correspondingly enhanced mortality rate in a choline-deficient and ethionine supplemented regime diet (CDE) provoked AP (Grady et al., 2000). In addition to the pro-inflammatory influences of SP in AP, it facilitates nociception in typical animal models representing AP.

\subsection{Chronic Pancreatitis}

Further, there are no sufficient efforts to evaluate the probable role of SP in chronic pancreatitis. SP was acknowledged as a facilitator of pain responses in the case of CP. Levels of NK1R mRNA in CP patients were considerably associated with the intensity, incidence, and interval of pain (Shrikhande et al., 2001). Comparable relationships were also witnessed between NK2R mRNA levels, coupled with pain (Michalski et al., 2007). A noticeable upsurge of SP comprised nerve endings which was witnessed from the swollen or inflammatory pancreatic tissue contrasted to healthy subjects (Büchler et al., 1992). Contrarywise this, intrapancreatic PPTA mRNA levels of expression were not enhanced in those patients, advocating that the site of SP synthesis is external to the pancreas (Di Sebastiano et al., 2000).

\section{Role of SP in Pancreatic Cancer}

In the preceding few years, the expression and release of peptides by the tumors have been a significant and expanding field of interest (Munoz \& Covenas, 2013). SP is an 11 aa long peptide that is extensively scattered all over the body. When SP binds to its highly specific receptor, NK1, it kicks off multiple biologic activities, such as the proliferation of tumor cells, angiogenesis (Guha et al., 2005), along with migration, which is crucial for the process of tumor cell infiltration and metastasis (Esteban et al., 2006; Muñoz et al., 2010). The mentioned biological functions are reversible using the NK1 receptor antagonists. These experimental findings insinuate that SP/NK1 receptor signaling may carry out an indispensable role in the process of cancer advancement and metastasis since SP could be a mitogen in tumor cells that express the NK1 receptor (Muñoz et al., 2010; Muñoz \& Rosso, 2010).

Also, SP, along with NK1 receptors, have been pinpointed in the neoplastic cells and peritumoral blood vessels (Hennig et al., 1995; Munoz et al., 2011; Muñoz et al., 2010). Furthermore, it has lately been described that the discharge of malignant tumor cells to the brain to develop cerebral metastases can be an SP stimulated process (Lewis et al., 2013). More precisely, it has been also testified that SP/NK1 receptor signalling is concerned with pancreatic cancer by provoking pancreatic cancer propagation, neo-angiogenesis, in addition to the movement of malignant pancreatic cells. Conflicting this, the NK1 receptor inhibits pancreatic tumor cell proliferation as well as angiogenesis. (Friess et al., 2003; Guha et al., 2005; Muñoz et al., 2006; Muñoz \& Rosso, 2010; Li et al., 2013).

The enriched expression levels of the NK1 receptor were not reported to be correlated to the tumor grade, although they were linked with an advanced tumor phase coupled with a feeble prognosis. In comparison to healthy individuals the immunoreactivity and mRNA expression levels of the NK1 receptor, are higher in pancreatic cancer test samples (Friess et. al., 2003). Furthermore, utilizing the western blot assessment, the NK1 receptor was noticed to be amplified 26-fold in the case of samples with pancreatic cancer when compared to normal healthy controls. Research suggests that the NK1 receptor mRNA was seen in 5 pancreatic cancer cell lines where the highest concentration via a quantitative RT-PCR was seen in CAPAN-1 and the lowest being ASPC-1 cell lines. It also suggested that SP along with its analog agonists stimulate pancreatic cancer progression based on the concentration of the respective NK1 receptor levels.

Moreover, this effect can be obstructed by a specific NK1 receptor inhibitor in a concentration subjected fashion (Friess et al., 2003; Muñoz et al., 2006). It is well-known that the possibility of progressing pancreatic cancer is exceedingly high in individuals with $\mathrm{CP}$ and probably is not dependent on country, gender, and the nature of pancreatitis (Lowenfels et al., 1993). It is also established that the process of up-regulation involved with mRNA expression levels of the NK1 receptor in CP has a convincing association with the pain disorder that these patients undergo (Shrikhande et al., 2001). Accordingly, excess expression of the engaged NK1 receptor may be involved in $\mathrm{CP}$ correlated with cancer. Truncated NK1 receptor is known to be overexpressed in colonic epithelial 
cells obtained from individuals with colitis-allied cancer; however, the entire length is not distressed (Gillespie et al., 2011).

\section{Pathological Role of SP in Inflammatory Diseases}

SP causes pain through a mechanism called nociception, in which the nocireceptor reacts to a potentially damaging stimulus by signalling the brain and the spinal cord alongside its proinflammatory mechanisms (Nichols et al., 1999). SP has known to be involved in numerous physiological responses and diseases. SP increases the sensitivity to pain due to its indirect inflammatory effects while some other literature also suggests that SP has an invitro pain-relieving effect that gives a possible explanation of the failure of NK-1R antagonists in clinical trials.

Interaction of SP with NK-1R triggers neurogenic inflammation augmenting the inflammatory process in several parts of the body (Gherardini et al., 2020). Neurogenic inflammation is characterized by vasodilation and increased vascular permeability to immune cells besides leucocyte extravasation and direct action upon resident infiltrating cells to augment their immune functions. There is a dynamic cross-talk between the nervous system and the immune system, a plausible answer for why the expression of SP and its receptor can be regulated by the immune cells (Green et al., 2019).

\subsection{Rheumatoid Arthritis (RA)}

The literature suggests that Substance $\mathrm{P}$ is found in higher concentrations in the synovial joints of patients suffering from RA as a result of which they stimulate the synovial cells, increasing the release of prostaglandins and collagenase from them (Keeble \& Brain, 2004). The number of the receptor of SP is different in the rheumatoid tissues pointing out their contribution to RA. Blocking the NK-1R is thought to be an efficient treatment strategy against RA (Menkes et al., 1993).

\subsection{Skin Disorders}

SP causes the accumulation of the mast cells, the WBC involved in allergic and inflammatory responses leading to eczema(Zhan et al., 2017). Higher blood concentrations of SP have been associated with psoriasis progression due to its role in inflammation and cell growth. SP has also been known to cause pruritus via the release of histamine from the skin mast cells (Amatya et al., 2010). Fibromyalgia patients have shown higher levels of SP in their spinal cord fluid, partly due to chronic stress, a key factor linked with fibromyalgia (Karlsson et al., 2019; Tsilioni et al., 2019).

\subsection{Inflammatory CNS Disorders}

Despite being highly protected by the blood-brain-barrier, neuroinflammation leads to infiltration of macrophages, T-cells, dendritic cells, and other immune responders due to the disruption of blood-brain-barrier by the pro-inflammatory substances like IL-12 secreted by the activated glial cells leading to devastating conditions like meningitis and encephalitis (Burmeister et al., 2017). Neurocysticercosis, a parasitic infection of the Central Nervous System caused by Taenia solium shows the presence of SP positive cells adjacent to the degenerating worms (Prodjinotho et al., 2020). In other CNS disorders like Parkinson's and Alzheimer's, a decreased level of SP has been reported in the animal models followed by a severe depletion in the NK1R expression neurons in MSA and Parkinson's disease (Przedborski, 2017; Severini et al., 2016). In some cases, the SP-NK1R interactive is required to reduce the disease burden such as murine gamma herpesvirus 68 and Salmonella infections driving the cell-mediated immunity for disease clearance showing the neuroprotective effects of this neuropeptide (Johnson et al., 2017; Rytel et al., 2020). However, the lack of SP-NK1R intection either due to the pharmacological response of NK1R antagonists or SP deficient mice contributes significantly to the bacteria-induced neuroinflammation and the consequent CNS damage.

\subsection{Asthma}

SP plays a major role in causing the typical changes in the asthmatic airways like bronchoconstriction, vasodilation, and plasma protein leakage, etc. by the activation of the postganglionic cholinergic nerves and mast cells. The expression of the NK-1R is upregulated in the asthmatic lung compared to normal making asthmatics hyper-responsive to SP. Steroid therapy may be used to down-regulate the expression of the NK-1R gene thereby curbing the SP-NK1R interactions (Kytikova et al., 2019).

Blocking the SP in the lungs increases the apoptosis of the lung cancer cells, a possible treatment option in non-small cell lung carcinoma patients. Targeting SP can also protect mice against TNF-alpha-mediated apoptotic liver damage. SP is also a key player in a non-apoptotic form of programmed cell death which is independent of caspase activation (Mashaghi et al., 2016).

\subsection{Gastrointestinal Tract Diseases}

Repeated acidification of the esophagus occurs in Gastrooesophageal reflux disease (GERD) due to the relaxation of the lower oesophageal sphincter causing SP release from the extrinsic afferent nerve endings activating local inhibitory pathways to the lower oesophageal sphincter via the neurokinin-1 receptors (Takeda et al., 2020). SP also plays a crucial role in regulating acute-pancreatitis and pancreatitis-associated lung injury since they are potent pancreatic circulatory stimulants (Suvas, 2017; Tamizhselvi et al., 2011). 


\subsection{Inflammatory Bowel Disease (IBD)}

The ulcerative colitis patients show elevated levels of SP in the rectum and colon while patients with Crohn's disease exhibit decreased mucosal levels of SP in the rectum (Patel et al., 2020). There is a 1000 fold up-regulation of SP binding sites in the lymphoid follicles and submucosal vasculature in patients suffering from IBD. Colonic inflammation triggers SP-induced inflammatory and proliferative effects leading to diseased conditions (Rychlik et al., 2020).

\subsection{Depression}

SP and NK-1R are present in abundance in those areas of the brain that are involved in emotion and behavioral stress response and hence patients with these mental health problems show significantly high levels of SP in the cerebrospinal fluid (Richter et al., 2018; Won et al., 2017).

\subsection{Sickle Cell Anaemia}

SP may be considered as a pain sensitization marker for sickle cell disease patients. SP promotes the production of cytokines that encourage adherence of the sickle red blood cells to the vessel wall, raising the risk of sickle cell crisis (Brandow et al., 2016).

\section{Conclusions}

Substance P, a member of the tachykinin family of neuropeptides is a critical molecule associated with inflammatory processes in a variety of tissues. As one of the very first messengers activated upon a stimulus, it plays an important role in pancreatic tissue injury/infection. Various other pathological conditions such as rheumatoid arthritis, skin disorders, inflammatory CNS disorders, asthma, gastrointestinal tract diseases, inflammatory bowel disease, and depression along with sickle cell anemia also see a very significant contribution of SP in their pathogenesis. In each case, SP plays a role in both - pain and progression of inflammation. However, resolving the inflammatory response is a dynamic series of events to prevent neutrophil sequestration, granulocyte clearance, and disruption in the homeostasis of the pro-and anti-inflammatory mediators. Therefore, the evolving role of SP in inflammation with better experimental evidence may help in the development of novel SP inhibitors in the future.

\section{Future Perspectives}

Since SP is an amplifier of inflammatory pathways, inhibition of SP could lead to a better prognosis of concerned tissues. A general curbing of SP activity, however, could affect surrounding cell types. On the other hand, specific blocking of SP activity in pancreatitis proves to be a promising pharmacological target. The NK-1R inhibitors against pancreatic conditions are not been well explored in vivo studies so far. Hence, they are not yet been clinically approved in any human pancreatic conditions so far. Further research in the area, thus shows the potential of better resolution of pancreatitis.

\section{Abbreviations}

AP- Acute pancreatitis; CCK-Cholecystokinin receptors; CDECholine-deficient and ethionine supplemented regime diet; $\mathrm{CP}$ Chronic pancreatitis; GERD- Gastro-oesophageal reflux disease; IBD - Inflammatory Bowel Disease; IL-8- Interleukin 8; IL-12Interleukin 12; MPO-Myeloperoxidase; NEP- Neutral endopeptidase; NF-кB-nuclear factor kappa B; NK1R-Neurokinin 1 Receptor; PPTA-Preprotachykinin A; SP-Substance P; TACRTachykinin receptor; TNF $\alpha$-Tumor Necrosis Factor $\alpha$; TRPV1Transient receptor potential vanilloid type 1; RA- Rheumatoid Arthritis; WBC- White blood cells.

\section{Conflicts Of Interest}

The authors declare that there are no potential conflicts of interest.

\section{Funding Sources}

The authors declare that no funding was received for the present study.

\section{References}

Amatya B, Nordlind K, Wahlgren CF (2010) Responses to intradermal injections of substance $\mathrm{P}$ in psoriasis patients with pruritus. Skin Pharmacology and Physiology 23(3): 133-138.

Ashton N, Argent BE, Green R (1990) Effect of vasoactive intestinal peptide, bombesin and substance $\mathrm{P}$ on fluid secretion by isolated rat pancreatic ducts. The Journal of Physiology 427(1): 471-482.

Bhatia M, Saluja AK, Hofbauer B, Frossard JL, Lee HS, Castagliuolo I, et al. (1998) Role of substance $\mathrm{P}$ and the neurokinin 1 receptor in acute pancreatitis and pancreatitis-associated lung injury. Proceedings of the National Academy of Sciences 95(8): $4760-4765$.

Bowden JJ, Garland AM, Baluk P, Lefevre P, Grady EF, Vigna SR, et al. (1994) Direct observation of substance P-induced internalization of neurokinin 1 (NK1) receptors at sites of inflammation. Proceedings of the National Academy of Sciences 91(19): 8964-8968.

Brandow AM, Wandersee NJ, Dasgupta M, Hoffmann RG, Hillery CA, Stucky CL, Panepinto JA (2016) Substance P is increased in patients with sickle cell disease and associated with haemolysis 
and hydroxycarbamide use. British Journal of Haematology 175(2): 237-245.

Büchler M, Weihe E, Friess H, Malfertheiner P, Bockman E, Müller S, et al. (1992) Changes in peptidergic innervation in chronic pancreatitis. Pancreas 7(2): 183-192.

Burmeister AR, Johnson MB, Chauhan VS, MoerdykSchauwecker MJ, Young AD, Cooley ID, et al., (2017) Human microglia and astrocytes constitutively express the neurokinin-1 receptor and functionally respond to substance P. Journal of Neuroinflammation 14(1): 1-11.

Couture R, Cuello AC (1984) Studies on the trigeminal antidromic vasodilatation and plasma extravasation in the rat. The Journal of Physiology 346(1): 273-285.

di Mola FF, di Sebastiano P (2008) Pain and pain generation in pancreatic cancer. Langenbeck's Archives of Surgery 393(6): 919922.

Di Sebastiano P, Di Mola FF, Di Febbo C, Baccante G, Porreca E, Innocenti P, et al. (2000) Expression of interleukin 8 (IL-8) and substance $\mathrm{P}$ in human chronic pancreatitis. Gut 47(3): 423-428.

Edwards AV, Bloom SR (1994) Pancreatic endocrine responses to substance $\mathrm{P}$ and calcitonin gene-related peptide in conscious calves. American Journal of Physiology-Endocrinology and Metabolism 267(6): E847-E852.

Esteban F, Munoz M, Gonzalez-Moles MA, Rosso M (2006) A role for substance $\mathrm{P}$ in cancer promotion and progression: a mechanism to counteract intracellular death signals following oncogene activation or DNA damage. Cancer and Metastasis Reviews 25(1): 137-145.

Figini M, Emanueli C, Grady EF, Kirkwood K, Payan DG, Ansel J, et al. (1997). Substance P and bradykinin stimulate plasma extravasation in the mouse gastrointestinal tract and pancreas. American Journal of Physiology-Gastrointestinal and Liver Physiology 272(4): G785-G793.

Friess H, Zhu Z, Liard V, Shi X, Shrikhande SV, Wang L, et al. (2003) Neurokinin-1 receptor expression and its potential effects on tumor growth in human pancreatic cancer. Laboratory Investigation 83(5): 731-742.

Gherardini J, Uchida Y, Hardman JA, Chéret J, Mace K, Bertolini M, Paus R (2020) Tissue-resident macrophages can be generated de novo in adult human skin from resident progenitor cells during substance P-mediated neurogenic inflammation ex vivo. PloS One 15(1): e0227817.
Gillespie E, Leeman SE, Watts LA, Coukos JA, O'Brien MJ, Cerda SR, et al. (2011) Truncated neurokinin-1 receptor is increased in colonic epithelial cells from patients with colitisassociated cancer. Proceedings of the National Academy of Sciences 108(42): 17420-17425.

Grady EF, Yoshimi SK, Maa J, Valeroso D, Vartanian RK, Rahim S, et al. (2000) Substance P mediates inflammatory oedema in acute pancreatitis via activation of the neurokinin-1 receptor in rats and mice. British Journal of Pharmacology 130(3): 505-512.

Green DP, Limjunyawong N, Gour N, Pundir P, Dong X (2019) A mast-cell-specific receptor mediates neurogenic inflammation and pain. Neuron 101(3): 412-420.

Guha S, Eibl G, Kisfalvi K, Fan RS, Burdick M, Reber H, et al. (2005) Broad-spectrum G protein-coupled receptor antagonist, [DArg1, D-Trp5, 7, 9, Leu11] SP: a dual inhibitor of growth and angiogenesis in pancreatic cancer. Cancer Research 65(7): 27382745 .

Helke CJ, Krause JE, Mantyh PW, Couture R, Bannon MJ (1990) Diversity in mammalian tachykinin peptidergic neurons: multiple peptides, receptors, and regulatory mechanisms. The FASEB Journal 4(6):1606-1615.

Hennig IM, Laissue JA, Horisberger U, Reubi J (1995) Substance-P receptors in human primary neoplasms: Tumoral and vascular localization. International Journal of Cancer 61(6): 786792.

Hökfelt T, Pernow B, Wahren J (2001) Substance P: a pioneer amongst neuropeptides. Journal of Internal Medicine 249(1): 2740.

Holzer P, Barthó L (1996) Sensory neurons in the intestine. Neurogenic Inflammation. CRC Press, Boca Raton, Pp. 153-167.

Horiuchi A, Iwatsuki K, Ren LM, Kuroda T, Chiba S (1993) Dual actions of glucagon: direct stimulation and indirect inhibition of dog pancreatic secretion. European Journal of Pharmacology 237(1): 23-30.

Hutter MM, Wick EC, Day AL, Maa J, Zerega EC, Richmond AC, et al. (2005) Transient receptor potential vanilloid (TRPV-1) promotes neurogenic inflammation in the pancreas via activation of the neurokinin-1 receptor (NK-1R). Pancreas 30(3): 260-265.

Johnson AR, Erdös EG (1973) Release of histamine from mast cells by vasoactive peptides. Proceedings of the Society for Experimental Biology and Medicine 142(4): 1252-1256. 
Johnson M, Young AD, Marriott I (2017) The therapeutic potential of targeting substance P/NK-1R interactions in inflammatory CNS disorders. Frontiers in Cellular Neuroscience 10: 296.

Karlsson B, Burell G, Kristiansson P, Björkegren K, Nyberg F, Svärdsudd K (2019) Decline of substance P levels after stress management with cognitive behaviour therapy in women with the fibromyalgia syndrome. Scandinavian Journal of Pain 19(3): 473482.

Katoh K, Murai K, Nonoyama T (1984) Effects of substance P on fluid and amylase secretion in exocrine pancreas of rat and mouse. Research in Veterinary Science 36(2): 147-152.

Keeble JE, Brain SD (2004) A role for substance P in arthritis? Neuroscience Letters 361(1-3): 176-179.

Kirkwood KS, Kim EH, He XD, Calaustro EQ, Domush C, Yoshimi SK, et al. (1999) Substance P inhibits pancreatic exocrine secretion via a neural mechanism. American Journal of Physiology-Gastrointestinal and Liver Physiology 277(2): G314G320.

Konturek SJ, Jaworek J, Tasler J, Cieszkowski M, Pawlik W (1981). Effect of substance P and its C-terminal hexapeptide on gastric and pancreatic secretion in the dog. American Journal of Physiology-Gastrointestinal and Liver Physiology 241(1): G74G81.

Kytikova OY, Novgorodtseva TP, Antonyuk MV, Gvozdenko TA (2019) The role of regulatory neuropeptides and neurotrophic factors in asthma pathophysiology. Russian Open Medical Journal 8(4). DOI: 10.15275/rusomj.2019.0402.

Lau HY, Wong FL, Bhatia M (2005) A key role of neurokinin 1 receptors in acute pancreatitis and associated lung injury. Biochemical and Biophysical Research Communications 327(2): 509-515.

Lewis KM, Harford-Wright E, Vink R, Nimmo AJ, Ghabriel MN (2013) Walker 256 tumour cells increase substance P immunoreactivity locally and modify the properties of the bloodbrain barrier during extravasation and brain invasion. Clinical \& Experimental Metastasis 30(1): 1-12.

Li X, Ma G, Ma Q, Li W, Liu J, Han L, et al. (2013) Neurotransmitter substance $P$ mediates pancreatic cancer perineural invasion via NK-1R in cancer cells. Molecular Cancer Research 11(3): 294-302.

Lotz M, Carson DA, Vaughan JH (1987) Substance P activation of rheumatoid synoviocytes: neural pathway in pathogenesis of arthritis. Science 235(4791): 893-895.
Lotz M, Vaughan JH, Carson DA (1988) Effect of neuropeptides on production of inflammatory cytokines by human monocytes. Science 241(4870): 1218-1221.

Lowenfels AB, Maisonneuve P, Cavallini G, Ammann RW, Lankisch PG, Andersen JR, et al. (1993) Pancreatitis and the risk of pancreatic cancer. New England Journal of Medicine 328(20): $1433-1437$.

Maa J, Grady EF, Yoshimi SK, Drasin TE, Kim EH, Hutter MM, et al. (2000) Substance P is a determinant of lethality in dietinduced hemorrhagic pancreatitis in mice. Surgery 128(2): 232239.

Mantyh PW, DeMaster E, Malhotra A, Rogers SD, Mantyh CR, Liu H, et al. (1995) Receptor endocytosis and dendrite reshaping in spinal neurons after somatosensory stimulation. Science 268(5217): 1629-1632.

Marriott I, Bost KL (2002) Substance P receptor mediated macrophage responses. In: Neuroimmune Circuits, Drugs of Abuse, and Infectious Diseases, Springer Publication, Pp. 247254.

Mashaghi A, Marmalidou A, Tehrani M, Grace PM, Pothoulakis C, Dana R (2016) Neuropeptide substance P and the immune response. Cellular and Molecular Life Sciences 73(22): 42494264.

Menkes CJ, Renoux M, Laoussadi S, Mauborgne A, Bruxelle J, Cesselin F (1993) Substance P levels in the synovium and synovial fluid from patients with rheumatoid arthritis and osteoarthritis. The Journal of Rheumatology 20(4): 714-717.

Michalski CW, Shi X, Reiser C, Fachinger P, Zimmermann A, Büchler MW, et al. (2007) Neurokinin-2 receptor levels correlate with intensity, frequency, and duration of pain in chronic pancreatitis. Annals of Surgery 246(5): 786-793.

Muñoz M, Rosso M (2010) The NK-1 receptor antagonist aprepitant as a broad spectrum antitumor drug. Investigational New Drugs 28(2): 187-193.

Munoz M, Covenas R (2013) Involvement of substance P and the NK-1 receptor in cancer progression. Peptides 48: 1-9.

Muñoz M, Rosso M, Coveñas R (2006) The NK-1 receptor is involved in the antitumoural action of L-733,060 and in the mitogenic action of substance $\mathrm{P}$ on human pancreatic cancer cell lines. Letters in Drug Design \& Discovery 3(5): 323-329.

Muñoz M, Rosso M, Coveñas R (2010) A new frontier in the treatment of cancer: NK-1 receptor antagonists. Current Medicinal Chemistry 17(6): 504-516. 
Munoz M, Rosso M, Covenas R (2011) The NK-1 receptor: a new target in cancer therapy. Current Drug Targets 12(6): 909-921.

Nathan JD, Patel AA, McVey DC, Thomas JE, Prpic V, Vigna SR, Liddle RA (2001) Capsaicin vanilloid receptor-1 mediates substance P release in experimental pancreatitis. American Journal of Physiology-Gastrointestinal and Liver Physiology 281(5): G1322-G1328.

Nichols ML, Allen BJ, Rogers SD, Ghilardi JR, Honore P, Luger NM, et al. (1999) Transmission of chronic nociception by spinal neurons expressing the substance $\mathrm{P}$ receptor. Science 286(5444): $1558-1561$.

Owman C (2019) Role of neural substance P and coexisting calcitonin gene-related peptide (CGRP) in cardiovascular function In: Nonadrenergic innervation of blood vessels, CRC Press, Pp. 77-100.

Patel M, Subas SV, Ghani MR, Busa V, Dardeir A, Marudhai S, Cancarevic I (2020) Role of Substance P in the Pathophysiology of Inflammatory Bowel Disease and Its Correlation With the Degree of Inflammation. Cureus 12(10):e11027. doi: 10.7759/cureus. 11027 .

Prodjinotho UF, Lema J, Lacorcia M, Schmidt V, Vejzagic N, Sikasunge C, et al. (2020) Host immune responses during Taenia solium Neurocysticercosis infection and treatment. PLoS Neglected Tropical Diseases 14(4): e0008005.

Przedborski S (2017) The two-century journey of Parkinson disease research. Nature Reviews Neuroscience 18(4): 251.

Qureshi GA (2007) Neurotransmission, Oxidative Stress, and Coexistence of Neurotransmitters in Parkinson's Disease. In: Qureshi GALI, SHBTOS, Parvez ND (Eds.). https://doi.org/https://doi.org/10.1016/B978-044452809-4/50159-9.

Richter F, Eitner A, Leuchtweis J, Bauer R, Ebersberger A, Lehmenkühler A, Schaible HG (2018) The potential of substance P to initiate and perpetuate cortical spreading depression (CSD) in rat in vivo. Scientific Reports 8(1): 1-13.

Rychlik A, Gonkowski S, Makowska K, Kaczmar E, Calka J (2020) Changes in the expression of substance $P$ in nerve fibres of the colonic mucosa in dogs suffering from inflammatory bowel disease. Acta Veterinaria Hungarica 68(2): 154-159.

Rytel L, Wojtkiewicz J, Snarska A, Mikołajczyk A (2020) Changes in the Neurochemical Characterization of Enteric Neurons in the Porcine Duodenum After Administration of LowDose Salmonella Enteritidis Lipopolysaccharides. Journal of Molecular Neuroscience 71: 1556-1566.
Schönfeld JV, Müller MK (1994) The islet-acinar axis of the pancreas: is there a role for glucagon or a glucagon-like peptide? Experientia 50(5): 442-446.

Severini C, Petrella C, Calissano P (2016) Substance P and Alzheimer's disease: emerging novel roles. Current Alzheimer Research 13(9): 964-972.

Shrikhande SV, Friess H, di Mola FF, Tempia-Caliera A, Garcia JRC, Zhu Z, et al. (2001) NK-1 receptor gene expression is related to pain in chronic pancreatitis. Pain 91(3): 209-217.

Singer MV, Gyr K, Sarles H (1985) Revised classification of pancreatitis: report of the Second International Symposium on the Classification of Pancreatitis in Marseille, France, March 28-30, 1984. Gastroenterology 89(3): 683-685.

Sjödin L, Dahlen HG, Gylfe E (1991) Calcium oscillations in guinea-pig pancreatic acinar cells exposed to carbachol, cholecystokinin and substance P. The Journal of Physiology 444(1): 763-776.

Sjödin L, Viitanen E, Gylfe E (1994) Rapid down-regulation of substance $\mathrm{P}$ binding to guinea-pig pancreatic acinar cells during homologous desensitization. The Journal of Physiology 476(1): $69-77$.

Song SY, Iwashita S, Noguchi K, Konishi S (1988) Inositol trisphosphate-linked calcium mobilization couples substance $\mathrm{P}$ receptors to conductance increase in a rat pancreatic acinar cell line. Neuroscience Letters 95(1-3): 143-148.

Suvas S (2017) Role of substance P neuropeptide in inflammation, wound healing, and tissue homeostasis. The Journal of Immunology 199(5): 1543-1552.

Takeda N, Takemura M, Kanemitsu Y, Hijikata H, Fukumitsu K, Asano T, et al. (2020) Effect of anti-reflux treatment on gastroesophageal reflux-associated chronic cough: Implications of neurogenic and neutrophilic inflammation. Journal of Asthma 57(11): 1202-1210.

Tamizhselvi R, Shrivastava P, Koh YH, Zhang H, Bhatia M (2011) Preprotachykinin-A gene deletion regulates hydrogen sulfideinduced toll-like receptor 4 signaling pathway in cerulein-treated pancreatic acinar cells. Pancreas 40(3): 444-452.

Tsilioni I, Pipis H, Freitag MSC, Izquierdo MDC, Freitag K, Theoharides TC (2019) Effects of an extract of salmon milt on symptoms and serum TNF and substance $\mathrm{P}$ in patients with fibromyalgia syndrome. Clinical Therapeutics 41(8): 1564-1574. 
V. Euler US, Gaddum JH (1931) An unidentified depressor substance in certain tissue extracts. The Journal of Physiology 72(1): 74-87.

Vera-Portocarrero L, Westlund KN (2005). Role of neurogenic inflammation in pancreatitis and pancreatic pain. Neurosignals 14(4): 158-165.

Watkins LR, Maier SF (2000) The pain of being sick: implications of immune-to-brain communication for understanding pain. Annual Review of Psychology 51(1): 29-57.

Won E, Kang J, Choi S, Kim A, Han KM, Yoon HK, et al, (2017) The association between substance $\mathrm{P}$ and white matter integrity in medication-naive patients with major depressive disorder. Scientific Reports 7(1): 1-8.

Xu XJ, Hao JX, Wiesenfeld-Hallin Z, Ha R, Folkers K, Ho T
(1991) Spantide II, a novel tachykinin antagonist, and galanin inhibit plasma extravasation induced by antidromic C-fiber stimulation in rat hindpaw. Neuroscience 42(3): 731-737.

Yan D, Liu X, Guo SW (2019) Neuropeptides substance P and calcitonin gene related peptide accelerate the development and fibrogenesis of endometriosis. Scientific Reports 9(1): 1-22.

Zhan M, Zheng W, Jiang Q, Zhao Z, Wang Z, Wang J, et al. (2017) Upregulated expression of substance P (SP) and NK1R in eczema and SP-induced mast cell accumulation. Cell Biology and Toxicology, 33(4): 389-405.

Zhou T, Wu N, Meng F, Venter J, Giang TK, Francis H, et al. (2018) Knockout of secretin receptor reduces biliary damage and liver fibrosis in Mdr2-/- mice by diminishing senescence of cholangiocytes. Laboratory Investigation 98(11): 1449-1464. 